\title{
Structure of Carbon Nanotubes in Colloidal Solutions under the Influence of a Constant Electric Field
}

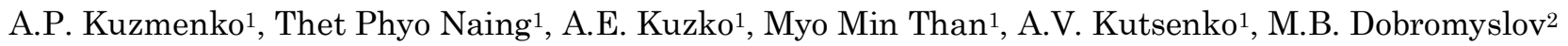 \\ 1 Southwest State University, 94, 50 let Oktyabrya st., 305040 Kursk, Russia \\ 2 Pacific National University, 136, Tikhookeanskaya st., 680035 Khabarovsk, Russia
}

(Received 04 May 2016; published online 03 October 2016)

\begin{abstract}
Processes of self-organization in diffusive and limited conditions of colloidal solutions of carbon nanotubes under the influence of constant electric fields are studied. It is established that functionalized MCNT - $\mathrm{COOH}$ in a drop of colloidal solution is oriented in an electric field in a controllable way, which is of great practical value.
\end{abstract}

Keywords: Multiwalled carbon nanotubes, Colloidal solutions, Ordered structures

DOI: 10.21272/jnep.8(3).03035

PACS numbers: 61.48.De, 82.70.Dd

\section{INTRODUCTION}

The high mechanical durability, heat conductivity and electrical conductivity, very low voltage of field emission, which are characteristic of carbon nanotubes (CNTs), along with high chemical and mechanical stability are substantially due to abnormally high aspect ratio $l / d$, which amounts to $10^{6}[1]$. All of these properties, and also abundance and availability of methods and ways of synthesis of CNTs both in the form of single-walled (SWCNTs) and multi-walled carbon (MWCNTs), cause their application promising in different fast-developing areas of engineering [2]. However, the application of SWCNTs and MWCNTs involves difficulties in stabilization and the set orientation. The alternative decision when SWCNTs and MWCNTs are structured can use the phenomena of self-assembly and self-organization [3]. The present work considers the influence of electric fields on self-organization processes of preliminary functionalized with carboxyl groups MWCNTs - $\mathrm{COOH}[4,5]$ with a different concentration in colloidal solutions of sodium dodecyl sulfate (SDS) with the deionized water (DW) and without SDS.

As samples for research were MWCNTs (Nanocyl production, Belgium) synthesized by CCVD method with nanocatalysts on the basis of $\mathrm{CoO}$. The level of functionalization of MWCNTs was determined by the use of FT-IR spectra (Nicolet iS50, 0,125 $\mathrm{cm}^{-1}$ ). The intensity of all lines in the range of measurements from 3435 to $624 \mathrm{~cm}^{-1}$ is noted to have changed by an order of magnitude. From MWCNTs - $\mathrm{COOH}$, which feature high stability, the colloidal solutions (CSs) either MWCNTs - COOH + SDS + DW $\quad(0.69 \mathrm{mg} / \mathrm{ml}) \quad$ or MWCNTs - COOH + DW $(0.2 \mathrm{mg} / \mathrm{ml})$ were prepared. An exponential change of the sizes of the initial agglomerates MWCNTs - $\mathrm{COOH}$ as a function of dispersion time $(t)$ is found: $D=D_{0} \exp (-k t)$, where $D_{0}$ is the largest diameter of agglomerate MWCNTs $-\mathrm{COOH}$ in an initial state; $k$ is time characteristic of a dispergator. The minimum diameter of the agglomerate, coincident with or multiple to MWCNTs diameter $d \sim 20 \mathrm{~nm}$, was probably the limit from below.

The produced CS was put with the drop method within the interelectrode space of the film chip presented in Fig. 1, a. Structurization of CS during evapo- ration at a constant voltage (from 10 to $50 \mathrm{~V}$ ) is studied. The motion of particles in an electric field in the evaporation was recorded with a video camera. By using video files, the dynamic analysis of particle behavior was conducted.

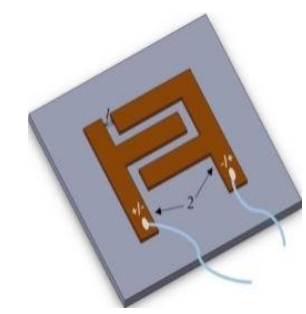

a

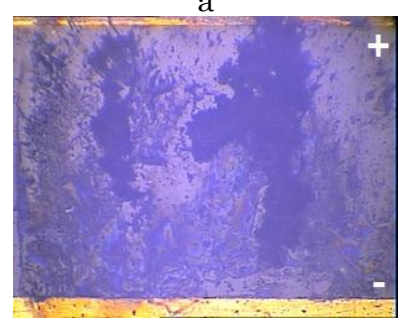

c

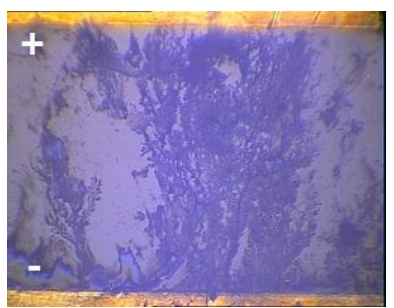

$\mathrm{b}$

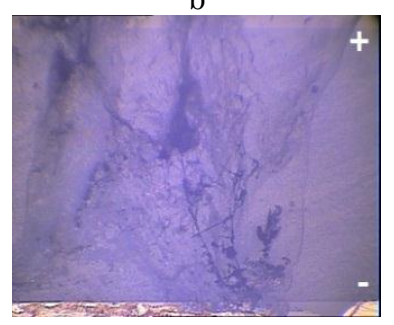

Fig. 1 - Images of a chip (a) and microstructures of a deposit from CS on polycrystalline glass for MWCNTs - COOH + DW: FS $U=15 \mathrm{~V}$ (b) and DS $U=16 \mathrm{~V}$ (c); for MWCNTs $\mathrm{COOH}+\mathrm{SDS}+\mathrm{DW}$ LPFs $U=45 \mathrm{~V}$ (d)

Fragments of instant confocal images of the structure at reorganization shown are in Figs. 1, b-d (with a distance between electrodes of $1500 \mu \mathrm{m}$; from below the cathode, from above - the anode). The structures MWCNTs + DW observed at $U=15$ and $16 \mathrm{~V}$ were systematized on the multilevel fractal structures (FSs) and the diffusion structures (DSs), respectively (see Fig. 1, b and c). And in MWCNTs + SDS + DW, the origination of piecewise linear (threadlike) structures (PLSs) (Fig. 1, d) was observed. Video control of particle motions revealed that the formation of FSs and PLSs occurred in one direction, namely, from the negative to the positive electrode.

Restructurings of MWCNTs $-\mathrm{COOH}+$ in a drop with electric influence according to the atomic force microscopy (AFM) are illustrated in Fig. 2, a, b. At a 
voltage of $16 \mathrm{~V}$, in some areas the formation of rectilinear enough structures of PLSs up to $450 \mathrm{~nm}$ long (Fig. 2 , a) was observed, which were composed of three separate agglomerates with a diameter of $150 \mathrm{~nm}$. It was found that when the voltage increased the diameter of the components of PLSs substantially reduced. So, at a voltage of $23 \mathrm{~V}$, this diameter actually became equal to the MWCNTs diameter of $20 \mathrm{~nm}$. Along with areas having PLSs, AFM made it possible to find the formation of spherical shape agglomerates with a diameter on the order of $230 \mathrm{~nm}$, which were made of separate MWCNTs with sizes, multiple $20 \mathrm{~nm}$. The formation from plaits of PLSs was also confirmed with the scanning electron microscopy (Fig. 2, c).

The analysis of dynamic behavior of particles in CS MWCNTs $-\mathrm{COOH}+\mathrm{DW}$ according to video data revealed that the formation of FSs from CS in DW solution began with $10 \mathrm{~V}$ and proceeded up to $20 \mathrm{~V}$. PLSs originated only at a voltage of $16 \mathrm{~V}$, and at greater voltage, the formation of areas with DS was observed. For CS from MCNTs - COOH + SDS + DW the growth of structures began starting with over $20 \mathrm{~V}$. At the first stage, there appeared DSs and only then PLSs originated.

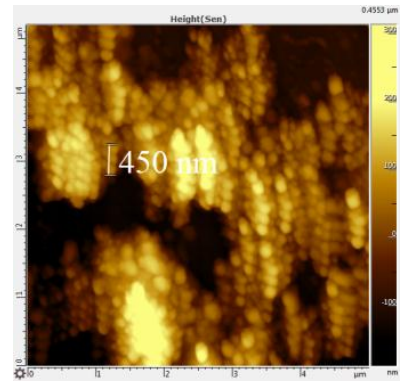

a

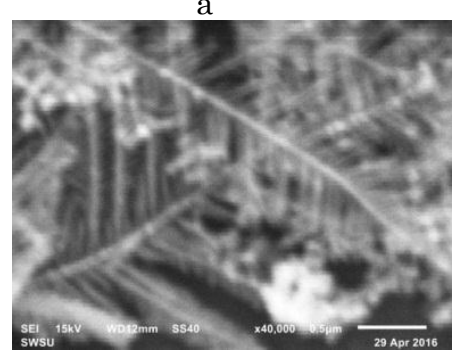

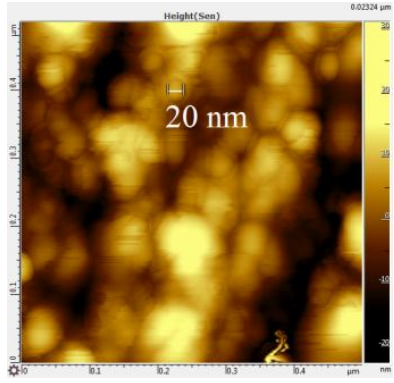

$\mathrm{b}$
Fig. 2 - AFM-images of PLSs structures from CS MWCNTs $\mathrm{COOH}+\mathrm{DW}$ in an electric field: $\mathrm{a}-16 \mathrm{~V} ; \mathrm{b}-23 \mathrm{~V}$ with sizes of $20 \mathrm{~nm}, \mathrm{c}-$ the electronic microscopic image of PLSs structures

It was established that from CS in DW solution the formation of FSs started with $10 \mathrm{~V}$ and continued up to $20 \mathrm{~V}$. PLSs arose only at $23 \mathrm{~V}$, and at a bigger voltage the formation of areas with DSs was observed. For CS from a SDS with the deionized water (MWCNTs $\mathrm{COOH}+\mathrm{SDS}+\mathrm{DW}$ ) structures began to grow with a voltage over $20 \mathrm{~V}$ when at the first stage there were DSs, and then PLSs. PLSs grew with acceleration (Fig. 3, a) and was also followed by the reduction in the sizes of the forming particles (Fig. 3, b).

The chemical composition of structures observed was studied by Raman scattering (RS) $\left(\right.$ Scope $^{\mathrm{TM}}$ omega the Raman microspectrometer, $\left.532 \mathrm{~nm}, 0.8 \mathrm{~cm}^{-1}\right)$. A spot of $500 \mathrm{~nm}$ diameter produced by focused radiation with a confocal microscope allowed one to obtain RS spectra from DSs, FSs and PLSs. The content of MWCNTs in them was confirmed by $D=1336-1353$ $\mathrm{cm}^{-1}$ and $G=1567-1600 \mathrm{~cm}^{-1}$ lines in the RS spectrum and by radial breathing modes $(\mathrm{RBM})=200$ $600 \mathrm{~cm}^{-1}$. Typical RS spectra are presented in Fig. 4. In them, CS MWCNTs $-\mathrm{COOH}+\mathrm{SDS}+\mathrm{DW}$ from PLSs featured the greatest intensity $\left(I_{D}\right.$ and $I_{G}$. For MWCNTs - $\mathrm{COOH}+\mathrm{DW}$ it was 4 times lower in the field of DSs, and in the FSs area, the intensity of these lines decreased by an order of magnitude. The amount of the relation $I_{\mathrm{D}} / I_{\mathrm{G}}$ determining the deficiency level was for structures of PLSs 1,27; for DSs increased up to 1,4, and for FSs amounted to 1,5. Essential changes in RS spectra in the RBM were observed. All of this confirmed that PLSs, DSs and FSs from MWCNTs $\mathrm{COOH}$ were created.

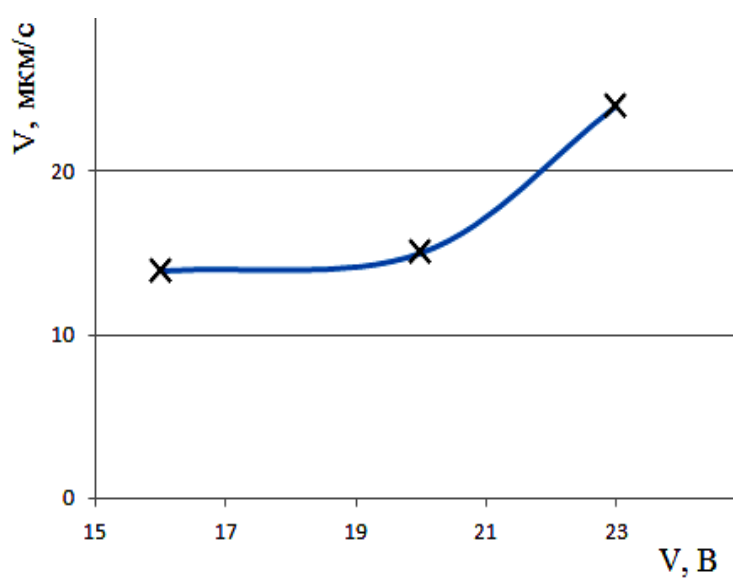

a

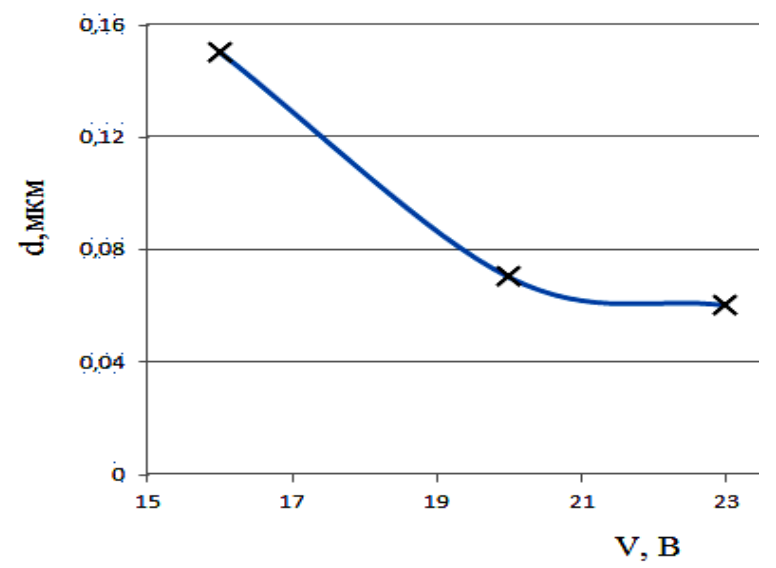

$\mathrm{b}$

Fig. 3 - Changes of speed of the particles motion according to video control (a) and the sizes of nanostructures with AFM images (b) versus the constant voltage amplitude and their predicted dependences

By UV-spectra (Shimadzu UV-1800, 190-1100 nm) the frequency of the plasmon resonance $(\omega \mathrm{PR})$ was determined, and through an optical threshold of absorption when the dependence $\alpha(\lambda)$ was extrapolated, the width of the forbidden zone $E_{\mathrm{g}}$ was calculated which were on $\omega_{\mathrm{PR}}=259$ and $257 \mathrm{~nm}, E_{\mathrm{g}}=4.5$ and $5.1 \mathrm{eV}$ for MWCNTs $-\mathrm{COOH}+\mathrm{DW}$ and MWCNTs - 
$\mathrm{COOH}+\mathrm{SDS}+\mathrm{DW}$, respectively. The coincidence of $\omega \mathrm{PR}$ is completely due to the identical size of the main component of the CS. Under the assumption that the size of these complexes is an area of coherence $(L)$ at a plasmon resonance the following condition will be satisfied: $d \sim L \sim \lambda$, from which it follows that the effective diameter of MWCNTs - COOH in CS amounts to about $260 \mathrm{~nm}$.

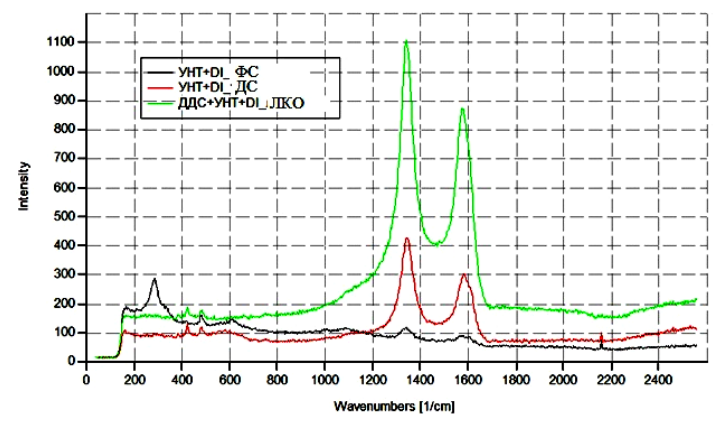

Fig. 4 - Raman spectra of FSs, DSs, and PLSs

The analysis of the AFM-images obtained (Fig. 2 a-c) revealed that with an increase in voltage the sizes $d$ of particles forming FSs, DSs and PLSs decreased (Fig. 3, b) whereas the motion speed of particles, according to video control, as a function of the constant voltage amplitude increased (Fig. 3, a). At the same time, if $d(U)$ corresponded to clearly hyperbolic dependence $d(U) \sim A / U$, then $V(U) \sim B U^{2}-$ parabolic one, where $A$ and $B$ are the generalized dimensional and normalizing multipliers.

For an explanation of the observed structuring processes of MWCNTs - COOH in CS, probably, the most significant contribution will be made by an electric force and surface tension. In the described conditions, the electrophoretic force begins to affect particles in CS between electrodes, whose value [6] is proportional to the square of the gradient of the applied electric field amplitude $\nabla E^{2}$ and to the cube of the particle radius $R^{3}$ :

\section{REFERENCES}

1. J.H. Lehman, M. Terrones, Carbon 49, 2581 (2011).

2. J. Prasek, J. Drbohlavova, J. Chomoucka, J. Mater. Chem. 21(40), 15872 (2011).

3. A.P. Kuz'menko, Chan Nyein Aung, V.V. Rodionov, Tech. Phys.+ 60(6), 903 (2015).

4. А.П. Кузьменко, Тет Пьо Наинг, Мьо Мин Тан, Известия Юго-Западного государственного университета.

$$
F_{\ni \Phi C}=2 \pi \varepsilon_{1} \pi(\omega) R^{3} \nabla E^{2},
$$

where $\varepsilon_{1}$ is the dielectric permeability of CS (it is taken equal $\varepsilon \mathrm{H} 2 \mathrm{O}=81 ; \operatorname{Re}|K(0)|$ - with consideration for $\omega=0$ is taken equal to 1 . The sizes of the particles forming FSs determined by AFM images vary depending on the amplitude of the applied voltage $d(U)$ (Fig. 3) and are in accord with the dependence (1).

It is possible to assume that MWCNTs $-\mathrm{COOH}$ in a drop in an electric field are polarized to form dipoles (Fig. 5) in the form of bundles (PLSs) of tubes with a radius $(D)$ up to $150 \mathrm{~nm}$ (Fig. 2), with the number of the constituent tubes: $D^{2 /} d^{2} \sim 50-100$. When the drop will be evaporated, the surface tension will build these bundles vertically, and the electric force will create groups of three and cause the directed movement from $«-»$ to «+».

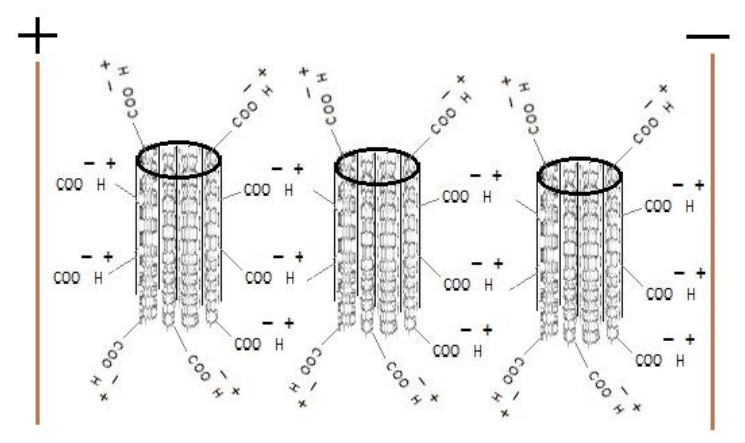

Fig. 5-A schematic representation of the MWCNTs $\mathrm{COOH}$ motion in an electric field

Thus, functionalized MWCNTs - $\mathrm{COOH}$ within a drop of CS put in an electric field are capable to be oriented in a controllable way, which is of great practical value.

Серия: Техника и технологии 3(16), 39 (2015) (A.P. Kuz'menko, Tet P'o Naing, M'o Min Tan, Izvestiya Yugo-Zapadnogo gosudarstvennogo universiteta. Seriya: Tekhnika i tekhnologii 3(16), 39 (2015)).

5. A.P. Kuzmenko, Thet Phyo Naing, Myo Min Than, J. Nanoelectron. Optoelectron. 7(4), 04014 (2015).

6. A. Kühnle, Curr. Opin. Colloid 14(2), 157 (2009). 